14.02

\title{
Изменение содержания оксида азота и меди в печени и гиппокампе крыс после моделирования ишемии головного мозга
}

\author{
() Х.Л. Гайнутдинов, ${ }^{1,2}$ В.В. Андрианов, ${ }^{1,2}$ Г.Г. Яфрарова, ${ }^{1,2}$ Л.В. Базан, ${ }^{1}$ Т.Х. Богодвид, ${ }^{2}$ С.Г. Пашкевич, ${ }^{3}$ \\ М.О. Досина, ${ }^{3}$ А.С. Замаро, ${ }^{3}$ А.А. Денисов, ${ }^{3}$ В.А. Кульчицкий ${ }^{3}$ \\ ${ }^{1}$ Казанский фиизико-технический институт им. Е.К. Завойского - обособленное структурное \\ подразделение ФИЦ КазНЦ РАН, \\ 420029 Казань, Россия \\ ${ }^{2}$ Казанский (Приволжский) фредеральный университет, \\ 420008 Казань, Россия \\ ${ }^{3}$ Институт фоизиологии НАН Беларуси, \\ 220072 Минск, Беларусь \\ e-mail: kh_gainutdinov@mail.ru
}

Поступило в Редакцию 28 декабря 2019 г.

В окончательной редакции 28 декабря 2019 г.

Принято к публикации 17 февраля 2020 г.

\begin{abstract}
Приведены результаты анализа содержания оксида азота и меди в печени и гиппокампе крыс после моделирования ишемии головного мозга. Исследования проведены методом спектроскопии электронного парамагнитного резонанса с использованием методики спиновых ловушек. Было показано, что содержание оксида азота на следующий день после моделирования ишемии мозга в гиппокампе снижалось в среднем на $50 \%$, в тканях печени наблюдалась тенденция к снижению. Через два дня после моделирования ишемии головного мозга содержание оксида азота в гиппокампе восстанавливалось, в печени наблюдалось достоверное увеличение в среднем на $46 \%$ относительно контрольных значений. Содержание меди, ассоциируемое с содержанием супероксиддисмутазы, в печени увеличивалось на вторые сутки постишемического периода в среднем в 2.5 раза, в гиппокампе достоверных изменений содержания меди не было обнаружено.
\end{abstract}

Ключевые слова: оксид азота, ЭПР-спектроскопия, ишемия мозга, медь, печень, гиппокамп.

DOI: $10.21883 / J T F .2020 .09 .49679 .432-19$

\section{Введение}

Функционирование тканей организма зависит от ряда факторов. Один из таких факторов - необходимость достаточного количества кислорода, который поставляется с током крови, для протекания окислительных процессов. Нехватка кислорода ведет к патологическим процессам в организме, предшественником которых является гипоксия $[1,2]$. Гипоксия - патологический процесс, возникающий при недостаточном снабжении тканей организма кислородом или нарушении его утилизации в процессе биологического окисления - состояние кислородного голодания как всего организма в целом, так и отдельных органов и тканей [2,3]; это важный компонент патогенеза многих заболеваний [4-6]. Гипоксия является универсальным патологическим состоянием при самых разнообразных заболеваниях человека сердечно-сосудистой и дыхательной недостаточности, ишемии миокарда, нарушении мозгового и периферического кровообращения и др. [2,5,7]. При недостатке снабжения кислородом организма и, в частности, мозга, возникает ишемия мозга, которая может завершиться ишемическим инсультом $[3,8]$.

При гипоксии нарушается функционирование нейромедиаторных систем, включая систему оксида азота (NO) [9]. NO известен как одна из важнейших сигналь- ных молекул, регулирующих физиологические функции организма и метаболизм клеток, он широко распространен в нервной системе [10,11]. Большой интерес вызывает участие NO в механизмах развития различных патологических состояний организма [10,12-14]. В настоящее время развитие ишемии мозга и последующее возникновение инсульта связывают с нарушениями мозгового кровотока, а также с нарушениями его регуляции системой NO [14-16]. NO выполняет свои физиологические функции, связываясь с ионами железа $(\mathrm{Fe})$ в составе гема, либо через $S$-нитрозилирование белков, а также принимает участие в целом ряде биохимических реакций $[10,17,18]$. Обнаружено, что при патологических процессах NO играет как протекторную роль, так и деструктивную, что определяется многими факторами [19].

Поэтому можно говорить о двух диаметрально противоположных влияниях NO: стимулирующее положительное и токсическое повреждающее действия [19]. Возможно, это связано с количеством оксида азота в тканях. Встает вопрос об использовании современного метода обнаружения и количественного определения содержания NO в тканях живых организмов в норме и при экспериментальном моделировании патологий.

Одним из наиболее эффективных методов обнаружения и количественного определения NO в биологических тканях является метод электронного парамагнитного 
резонанса (ЭПР) [17,20,21]. Эффективность метода обусловлена методикой, разработанной Ваниным и др. [22], которая основана на реакции радикала (в данном случае $\mathrm{NO}$ ) со спиновой ловушкой. В результате реакции образуется аддукт с характерным спектром ЭПР. Авторы применили комплекс $\mathrm{Fe}^{2+}$ с диэтилдитиокарбаматом (DETC) для захвата $\mathrm{NO}$ и формирования устойчивого тройного комплекса $(\mathrm{DETC})_{2}-\mathrm{Fe}^{2+}-\mathrm{NO}$ в различных тканях животных. Эти комплексы характеризуются легко распознаваемым спектром ЭПР со значением $g$-фактора 2.035-2.040 и триплетной сверхтонкой структурой $[17,21,23]$. Метод обладает чувствительностью $0.04-0.4 \mathrm{nM}$, позволяет проводить прямые измерения, является высокочувствительным за счет применения спиновых ловушек [24].

Ранее нашим коллективом методом ЭПР спектроскопии была проведена оценка in vivo влияния ишемического инсульта на интенсивность продукции $\mathrm{NO}$ в тканях мозга, сердца и печени крыс [25]. Для моделирования ишемического инсульта животные были подвергнуты 5 min гипобарической гипоксии (условный подъем на высоту $4500 \mathrm{~m}$ над уровнем моря), в этом случае ишемии подвергается весь организм. Целью настоящей работы было исследование методом ЭПР-спектроскопии интенсивности продукции $\mathrm{NO}$ и содержания меди (как показателя супероксиддисмутазы) в тканях печени, а также в гиппокампе крыс при моделировании ишемии мозга с помощью перевязки общих сонных артерий $[26,27]$, что позволяет подвергать ишемическому воздействию только головной мозг.

\section{1. Методика эксперимента}

Моделирование ишемического инсульта осуществляли в соответствии с утвержденным протоколом Комиссии по этике Института физиологии Национальной академии наук Беларуси (НАН Беларуси), г. Минск. Моделирование ишемии головного мозга осуществляли лигированием (перевязкой) общих сонных артерий на уровне бифуркации у крыс-самцов линии Вистар $(n=10)$ под кетамин-ксилазин-ацепромазиновым наркозом $[26,27]$. Вторую группу составляли интактные животные $(n=10)$, которые не подвергались хирургическим манипуляциям в области мозга. За $30 \mathrm{~min}$ до извлечения исследуемых тканей животным вводили компоненты спиновой ловушки для NO. Ткани печени, а также гиппокамп извлекались под кетамин-ксилазин-ацепромазиновым наркозом, образцы сразу замораживались в жидком азоте.

При подготовке образцов для измерения ЭПР спектров мы опирались на методику спиновых ловушек, предложенную проф. А.Ф. Ваниным с сотрудниками $[17,28]$. Нами в качестве спиновой ловушки был применен комплекс $\mathrm{Fe}^{2+}$ с диэтилдитиокарбаматом $(\mathrm{DETC})_{2}-\mathrm{Fe}^{2+}$. Комплекс спиновой ловушки с $\mathrm{NO}$

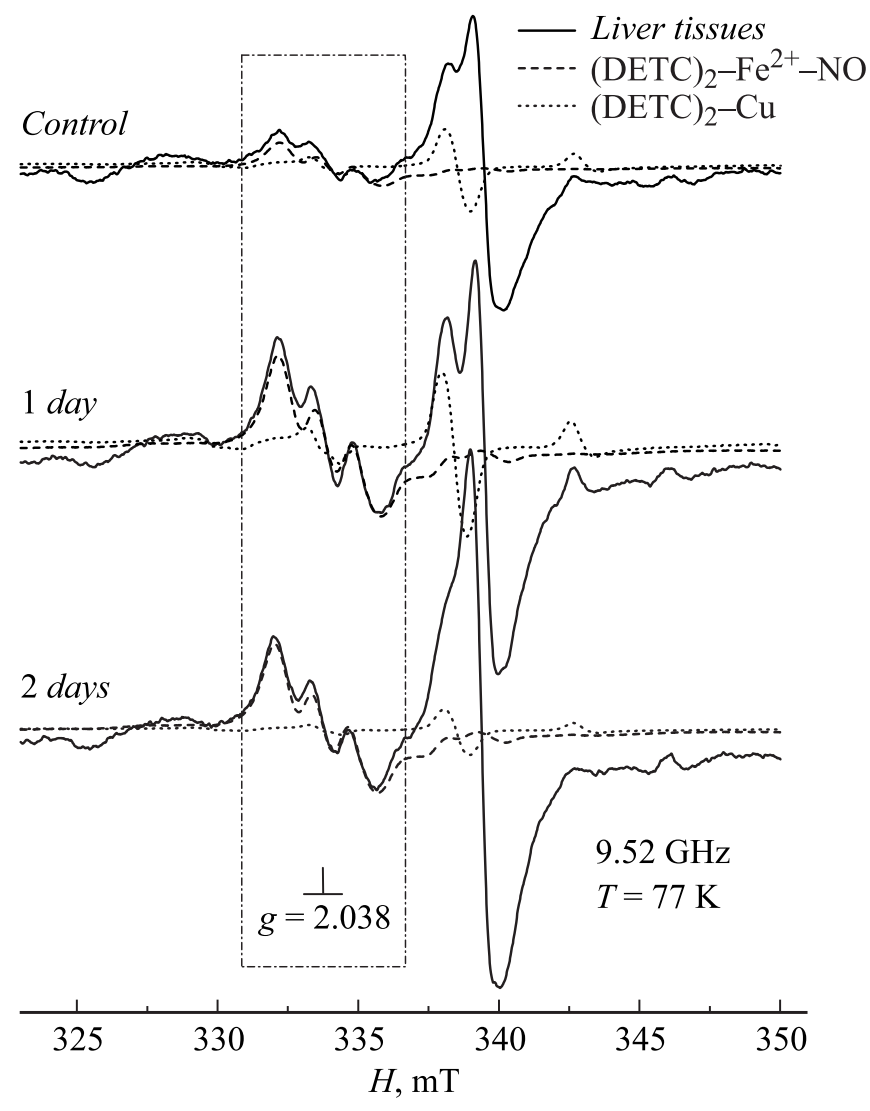

Рис. 1. Спектры ЭПР ткани печени интактной крысы („Control“), крысы на следующий день („1 day“) и через 2 дня (,2 days") после моделирования ишемии мозга. Крысы были инъецированы компонентами спиновой ловушки для образования комплекса $(\text { DETC })_{2}-\mathrm{Fe}^{2+}-\mathrm{NO}$. Ось абсцисс - магнитное поле.

$\left((\mathrm{DETC})_{2}-\mathrm{Fe}^{2+}-\mathrm{NO}\right)$ характеризуется легко распознаваемым спектром ЭПР со значением $g$-фактора 2.038 и триплетной сверхтонкой структурой $[14,17,21]$. Как и ранее [20], DETC-Na вводили внутрибрюшинно в дозе $500 \mathrm{mg} / \mathrm{kg}$ в $2.5 \mathrm{ml}$ воды. Смесь растворов сульфата железа $\left(\mathrm{FeSO}_{4} \cdot 7 \mathrm{H}_{2} \mathrm{O}\right.$, Sigma, USA) в дозе $37.5 \mathrm{mg} / \mathrm{kg}$ и цитрата натрия в дозе $187.5 \mathrm{mg} / \mathrm{kg}$ (в объеме $1 \mathrm{ml}$ воды на $300 \mathrm{~g}$ веса животного), приготовленную непосредственно перед введением, вводили подкожно в три точки - правое и левое бедро и в ростральную часть межлопаточной области. В смеси сульфата железа и цитрата натрия образуется цитрат железа. DETC-Na и цитрат железа распределяются по организму и при взаимодействии образуют нерастворимый в воде комплекс $\mathrm{DETC}-\mathrm{Fe}^{2+}$, способный взаимодействовать с $\mathrm{NO}$ с образованием стабильного радикала $(\text { DETC })_{2}-\mathrm{Fe}^{2+}-\mathrm{NO}$, который может быть зарегистрирован методом ЭПРспектроскопии. Компоненты спиновой ловушки для оксида азота (DETC- $\mathrm{Na}, \mathrm{FeSO}_{4}$, sodium citrate) вводили животным за 30 min до извлечения исследуемых тканей. Образцы тканей (печени и гиппокампа) сразу замораживались в жидком азоте и в замороженном состоянии 

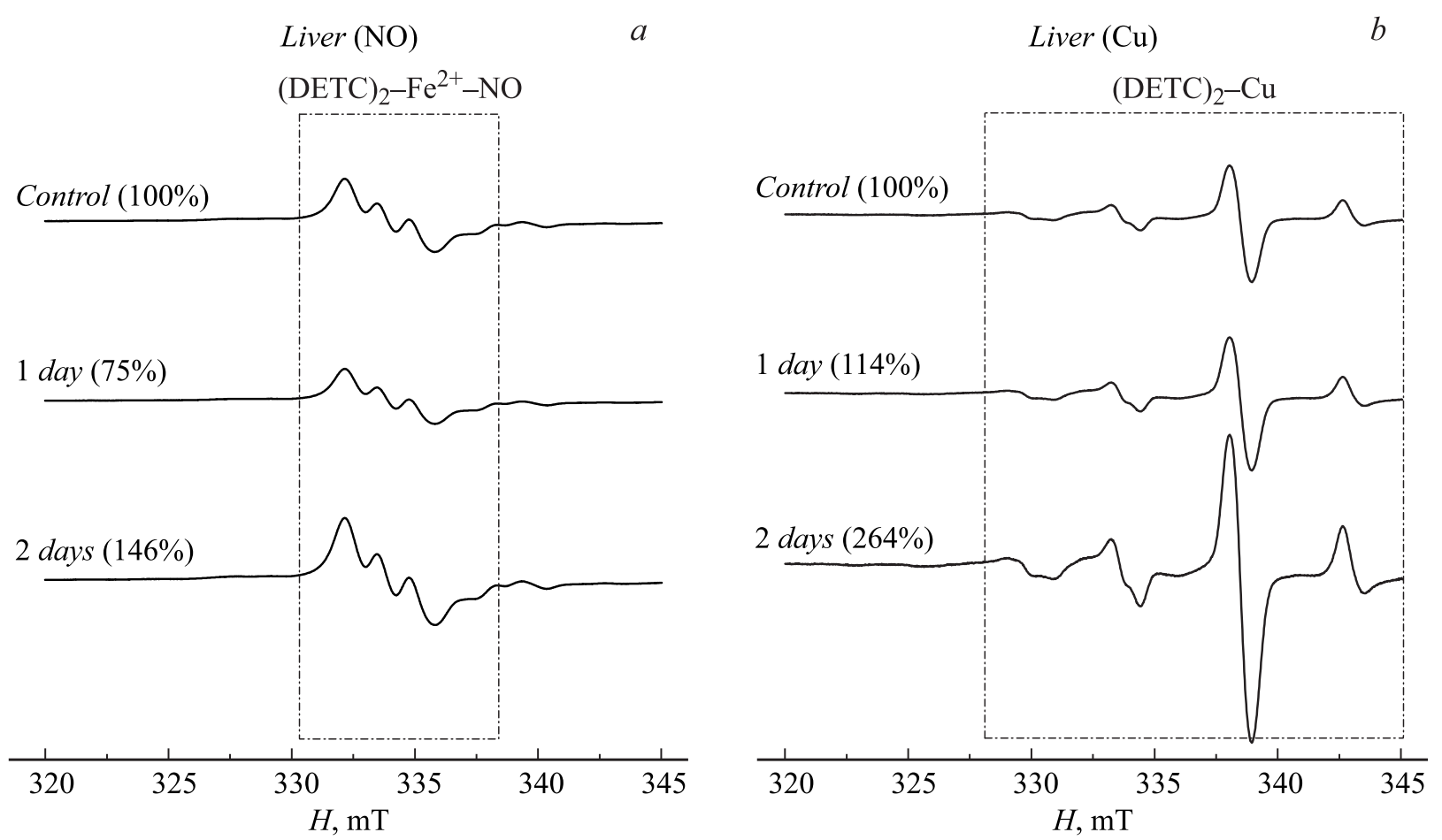

Рис. 2. Средние сигналы комплексов $(\mathrm{DETC})_{2}-\mathrm{Fe}^{2+}-\mathrm{NO}(a)$ и $(\mathrm{DETC})_{2}-\mathrm{Cu}(b)$, выделенные из спектров ЭПР тканей печени интактной крысы („Control“), крысы на следующий день („1 day“) и через 2 дня („2 days“) после моделирования ишемии мозга. Штрихпунктиром показаны области комплексов $(\mathrm{DETC})_{2}-\mathrm{Fe}^{2+}-\mathrm{NO}(a)$ и $(\mathrm{DETC})_{2}-\mathrm{Cu}(b)$ в наблюдаемом сигнале. Процентами показаны средние уровни сигналов этих комплексов. Ось абсцисс - магнитное поле.

перевозились из Минска в Казань в пластиковых контейнерах с сухим льдом. Комплекс спиновой ловушки c NO ((DETC $\left.)_{2}-\mathrm{Fe}^{2+}-\mathrm{NO}\right)$ в таком состоянии хорошо сохраняется, и сигнал от комплекса не изменяется не менее месяца. Масса образцов составляла около $100 \mathrm{mg}$.

Спиновая ловушка взаимодействует также $\mathrm{c} \mathrm{Cu}$, образуя комплекс $\mathrm{Cu}(\mathrm{DETC})_{2}$, который также может быть зарегистрирован методом ЭПР-спектроскопии [29]. Измерения спектров комплексов (DETC $)_{2}-\mathrm{Fe}^{2+}-\mathrm{NO}$ и $\mathrm{Cu}(\mathrm{DETC})_{2}$ проводили на спектрометрах фирмы Брукер X диапазона $(9.50 \mathrm{GHz}) \mathrm{EMX} /$ plus с температурной приставкой ER 4112HV и ER $200 \mathrm{SRC}$ при модуляции магнитного поля $100 \mathrm{kHz}$, амплитуды модуляции $2 \mathrm{G}$, мощности СВЧ излучения $30 \mathrm{~mW}$, временной константе $200 \mathrm{~ms}$ и температуре $77 \mathrm{~K}$ в пальчиковом дьюаре фирмы Брукер. Амплитуда модуляции, усиление и мощность СВЧ во всех экспериментах подбирались с условием отсутствия перемодуляции и насыщения сигнала ЭПР и сохранялись одинаковыми на протяжении всех измерений.

\section{2. Результаты исследований и их обсуждение}

Нами было проведено исследование интенсивности продукции NO и содержания меди (как показателя супероксиддисмутазы) в тканях печени, а также в гиппокампе крыс после моделирования ишемии мозга. Моделирование ишемии мозга осуществляли перевязкой общих сонных артерий [26,27], что позволяет подвергать ишемическому воздействию только головной мозг, а не весь организм, как было в нашей предыдущей работе [25]. Пример спектра ЭПР тканей печени интактной (контроль) крысы и крыс через 1 и 2 дня после моделирования ишемии головного мозга приведен на рис. 1. На этих спектрах видны характерный триплетный сигнал от комплекса $(\text { DETC })_{2}-\mathrm{Fe}^{2+}-\mathrm{NO}$ со значением g-фактора, равным 2.038, и сигнал от меди $[14,17,24,28]$. Эти сигналы $\left((\mathrm{DETC})_{2}-\mathrm{Fe}^{2+}-\mathrm{NO}\right)$ и $\left((\mathrm{DETC})_{2}-\mathrm{Cu}\right)$ были выделены из общего спектра ЭПР для тканей печени (рис. 2) и гиппокампа (рис. 3).

На следующий день после моделирования ишемии головного мозга содержание $\mathrm{NO}$ в тканях печени имело тенденцию к снижению (рис. $4, a$ ), а в гиппокампе и достоверно снижалось в среднем на $50 \%$ (рис. 5, $a$ ). Через 2 дня после моделирования ишемии мозга содержание NO восстанавливалось в гиппокампе и достоверно увеличивалось (в среднем на 46\%) в тканях печени. Ранее нами при моделировании ишемии всего организма методом гипобаричекой гипоксии (условный подъем на высоту) нами было получено более значительное снижение содержания NO в тканях организма, и такое же в мозге [25]. Полученные результаты показывают, что при моделировании ишемии всего организма 

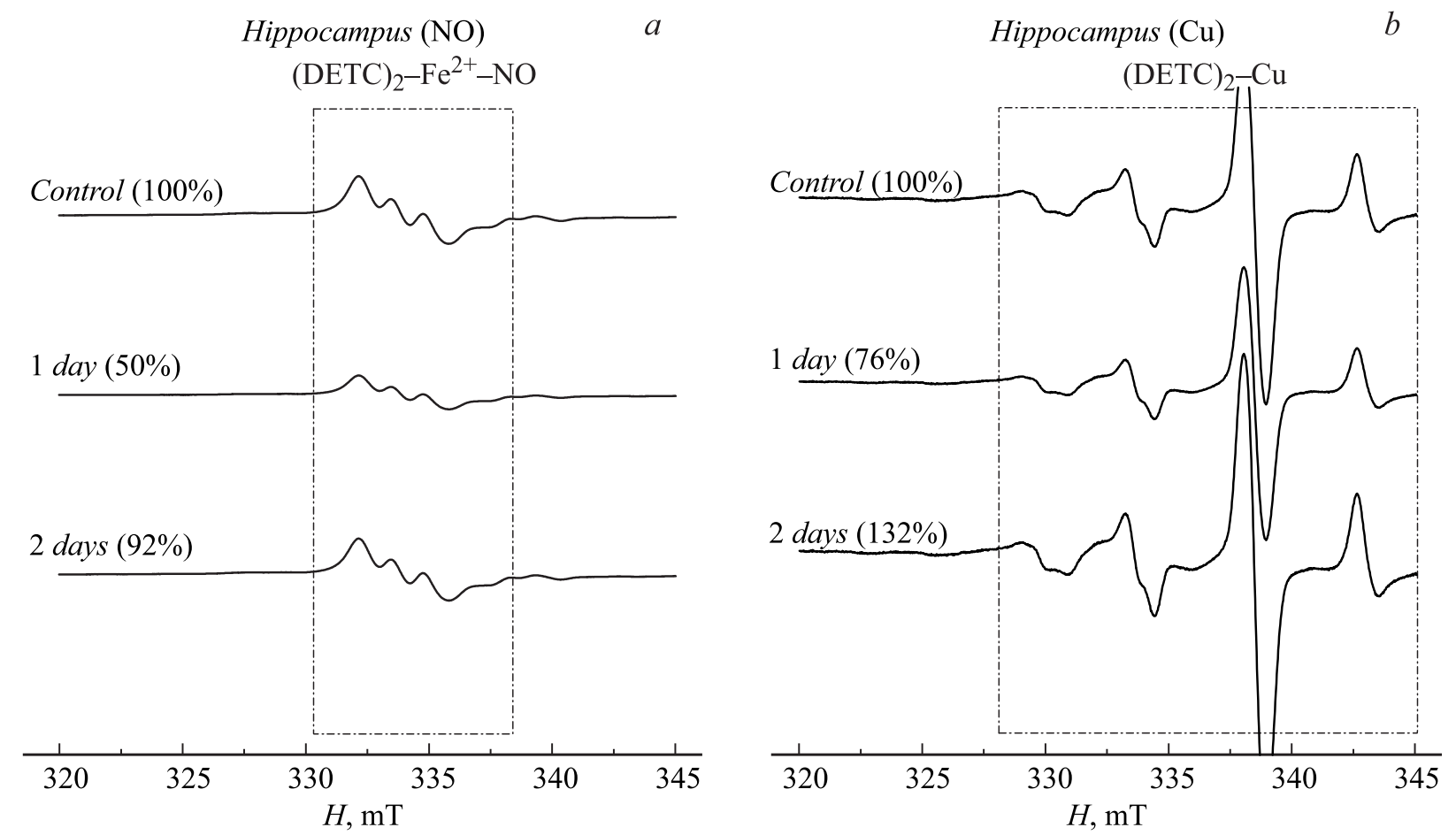

Рис. 3. Средние сигналы комплексов $(\mathrm{DETC})_{2}-\mathrm{Fe}^{2+}-\mathrm{NO}(a)$ и $(\mathrm{DETC})_{2}-\mathrm{Cu}(b)$, выделенные из спектров ЭПР тканей гиппокампа интактной крысы („Control"), крысы на следующий день („1 day“) и через 2 дня („2 days“) после моделирования ишемии мозга. Штрихпунктиром показаны области комплексов $(\mathrm{DETC})_{2}-\mathrm{Fe}^{2+}-\mathrm{NO}(a)$ и $(\mathrm{DETC})_{2}-\mathrm{Cu}(b)$ в наблюдаемом сигнале. Процентами показаны средние уровни сигналов этих комплексов. Ось абсцисс - магнитное поле.
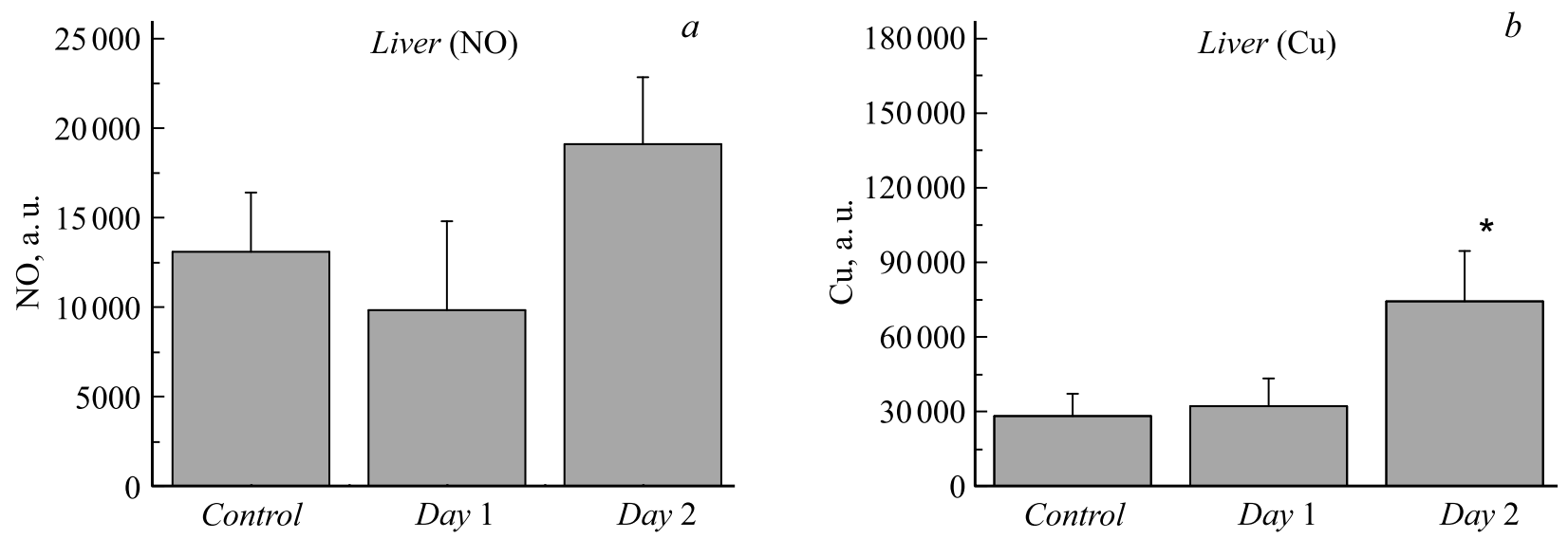

Рис. 4. Относительное содержание NO $(a)$ и $\mathrm{Cu}(b)$ в тканях печени интактной крысы („Control“), крысы на следующий день $($ (1 day“) и через 2 дня („2 days“) после моделирования ишемии мозга. Показаны: средние значения и стандартные ошибки среднего, ${ }^{*}$ - отличие от контроля (t-test, $\left.p<0.05\right)$. Ось ординат - средняя интегральная интенсивность (а.u.) сигнала комплексов $(\text { DETC })_{2}-\mathrm{Fe}^{2+}-\mathrm{NO}$ и $(\mathrm{DETC})_{2}-\mathrm{Cu}$.

продукция NO изменяется в тканях периферических органов сильнее, чем при ишемии мозга. В то же время изменение продукции $\mathrm{NO}$ в мозге при моделировании ишемии головного мозга и моделировании ишемии всего организма примерно одинаково. Есть предположение, что после всплеска продукции $\mathrm{NO}$ в первые часы $[30,31]$ происходит истощение содержания $L$-аргинина, который был израсходован в начальные минуты, часы после ишемии/гипоксии [32]. Возможно, по этой причине при моделировании ишемии всего организма снижение содержания NO на первые сутки в тканях более выражено.

Содержание меди на следующий день после моделирования ишемии головного мозга в тканях печени не изменялось (рис. $4, b$ ), и наблюдалась тенденция к снижению в гиппокампе (рис. $5, b)$. Через 2 дня после моделирования ишемии головного мозга содержание меди недосто- 

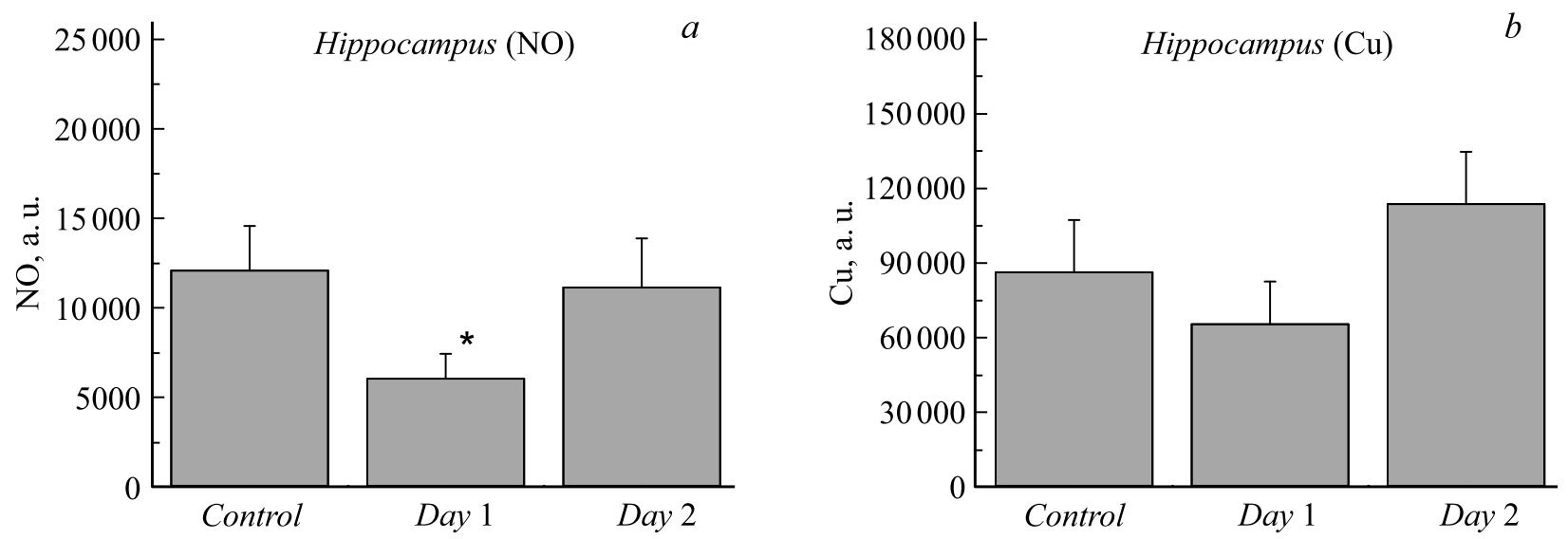

Рис. 5. Относительное содержание NO $(a)$ и $\mathrm{Cu}(b)$ в тканях гиппокампа интактной крысы („Control“), крысы на следующий день („1 day“) и через 2 дня („2 days“) после моделирования ишемии мозга. Показаны: средние значения и стандартные ошибки среднего, ${ }^{*}$ - отличие от контроля (t-test, $\left.p<0.05\right)$. Ось ординат - средняя интегральная интенсивность (а.u.) сигнала комплексов $(\text { DETC })_{2}-\mathrm{Fe}^{2+}-\mathrm{NO}$ и $(\text { DETC })_{2}-\mathrm{Cu}$.

верно увеличивалось в гиппокампе, а в тканях печени наблюдали увеличение в среднем в 2.5 раза. Дисмутирование супероксида с помощью цитозольного фермента $\mathrm{Cu}, \mathrm{Zn}-\mathrm{COD}$ (супероксиддисмутаза) является первичной и основной защитой от процессов свободнорадикального окисления $[10,12]$. Нами показано, что содержание меди, ассоциируемое с содержанием супердисмутазы, в тканях печени и гиппокампе не изменяется через сутки после моделирования ишемии и увеличивается через 2 дня после моделирования ишемии (в печени достоверно). Это демонстрирует сохранение в течение этого времени активности системы антиоксидантной защиты, а на вторые сутки даже усиление в печени, которая может противодействовать гипоксическим факторам. Полученные результаты могут помочь в исследованиях основ для создания лекарств разнообразного терапевтического действия [33].

\section{Заключение}

Нами было проведено исследование интенсивности продукции NO и содержания меди (как показателя супероксиддисмутазы) в тканях печени, а также в гиппокампе крыс после ишемии мозга. Моделирование ишемии мозга осуществляли перевязкой общих сонных артерий; при такой методике осуществляется ишемическое воздействие только на мозг, а не на весь организм, как это бывает при гипобарической гипоксии (условный подъем на высоту). Полученные результаты показывают, что при моделировании ишемии всего организма продукция NO изменяется в тканях периферических органов сильнее, чем при ишемии мозга. В то же время продукция NO в мозге изменяется при моделировании ишемии мозга и моделировании ишемии всего организма примерно одинаково.

\section{Финансирование работы}

Работа выполнена при частичной поддержке РФФИ (грант № 18-515-00003) и БРФФИ (грант Б18Р-227), измерение образцов за счет государственного задания ФИЦ КазНЦ РАН.

\section{Конфликт интересов}

Авторы заявляют, что у них нет конфликта интересов.

\section{Список литературы}

[1] Kumar H., Choi D.-K. // Mediators of Inflammation. 2015. ID 584758. http://dx.doi.org/10.1155/2015/584758

[2] Voronina T.A. // Rev. Clinical Pharmacology and Drug Therapy. 2016. Vol. 14. N 1. P. 63-70.

[3] Lo E.H., Dalkara T., Moskowitz M.A. // Nat. Rev. Neurosci. 2003. Vol. 4. N 5. P. 399-415.

[4] Dirnagl U., Iadecola C., Moskowitz M.A. // Trends Neurosci. 1999. Vol. 22. N 9. P. 391-397.

[5] Novikov V.E., Katunina N.P. // Rev. Clinical Pharmacology and Drug Therapy. 2002. Vol. 1. N 2. P. 73-87.

[6] Donnan G.A., Fisher M., Macieod M., Davis S.M. // Stroke. Lancet. 2008. Vol. 371. P. 1612-1623.

[7] LaManna J.C., Chavez J.C., Pichiule P. // J. Experim. Biol. 2004. Vol. 207. P. 3163-3169. DOI: $10.1242 / \mathrm{jeb} .00976$

[8] Doyle K.P., Simon R.P., Stenzel-Poore M.P. // Neurophrmacology. 2008. Vol. 55. P. 310-318.

[9] Manukhina E.B., Malyshev I.Y., Smirin B.V., Mashina S.Y., Saltykova V.A., Vanin A.F. // Nitric Oxide. 1999. Oct. Vol. 3. N 5. P. 393-401.

[10] Steinert J.R., Chernova T., Forsythe I.D. // Neuroscientist. 2010. August. Vol. 16. N 4. P. 435-452. DOI: $10.1177 / 1073858410366481$

[11] Vanin A.F. // Nitric Oxide. 2016. Vol. 54. P. 15-29.

[12] Pacher P., Beckman J.S., Liaudet L. // Physiol. Rev. 2007. Vol. 87. P. 315-427. 
[13] Реутов В.П., Охотин В.Е., Шуклин А.В., Сорокина Е.Г., Косицын Н.С., Гурин В.Н. // УФН. 2007. Т. 38. № 4. С. 39 58.

[14] Gainutdinov Kh.L., Gavrilova S.A., Iyudin V.S., Golubeva A.V., Davydova M.P., Jafarova G.G., Andrianov V.V., Koshelev V.B. // Appl. Magn. Resonance. 2011. Vol. 40. N 3. P. 267-278.

[15] Manukhina E.B., Downey H.F., Mallet R.T. // Exp. Biol. Med. 2006. Vol. 231. P. 343-365.

[16] Terpolilli N.A., Moskowitz M.A., Plesnila N. // J. Cereb. Blood. Flow. Metab. 2012. Vol. 32. N 7. P. 1332-1346.

[17] Vanin A.F., Huisman A., Van Faassen E.E. // Methods in Enzymology. 2003. Vol. 359. P. 27-42.

[18] Hill B.G., Dranka B.P., Bailey S.M., Lancaster J.R., DarleyUsmar V.M. // J. Biol. Chem. 2010. Vol. 285. P. 19699-19704.

[19] Calabrese V., Cornelius C., Rizzarelli E., Owen J.B., Dinkova-Kostova A.T., Butterfield D.A. // Antioxidants and Redox Signaling. 2009. Vol. 11. P. 2717-2739.

[20] Ismailova A.I., Gnezdilov O.I., Muranova L.N., Obynochny A.A., Andrianov V.V., Gainutdinov Kh.L., Nasyrova A.G., Nigmatullina R.R., Rahmatullina F.F., Zefirov A.L. // Appl. Magn. Reson. 2005. Vol. 28. P. 421-430.

[21] Hogg N. // Radical Biology \& Medicine. 2010. Vol. 49. P. $122-129$.

[22] Vanin A.F., Mordvintcev P.I., Kleshchev A.L. // Studia Biophis. 1984. Vol. 102. P. 135-143.

[23] Гайнутдинов Х.Л., Андрианов В.В., Июдин В.С., Юртаева С.В., Яфарова Г.Г., Файзуллина Р.И., Ситдиков Ф.Г. // Биофизика. 2013. Т. 58. № 2. С. 276-280. [Gainutdinov Kh.L., Andrianov V.V., Iyudin V.S., Yurtaeva S.V., Jafarova G.G., Faisullina R.I., Sitdikov F.G. // Biophys. 2013. Vol. 58. N 2. P. 203-205.]

[24] Kleschyov A.L., Wenzel P., Munzel T. // J. Chromatography B. 2007. Vol. 851. P. 12-20.

[25] Andrianov V.V., Pashkevich S.G., Yafarova G.G., Denisov A.A., Iyudin V.S., Bogodvid T.Kh., Dosina M.O., Kulchitsky V.A., Gainutdinov Kh.L. // Appl. Magn. Res. 2016. Vol. 47. N 9. P. 965-976.

[26] Deryagin O.G., Gavrilova S.A., Gainutdinov Kh.L., Golubeva A.V., Andrianov V.V., Yafarova G.G., Buravkov S.V., Koshelev V.B. // Frontiers in Neuroscence. 2017. Vol. 11. $\mathrm{N} 427$.

[27] Shanko Y., Zamaro A., Takalchik S.Y., Koulchitsky S., Pashkevich S., Panahova E., Navitskaya V., Dosina M., Denisov A., Bushuk S., Kulchitsky V. // J. Sci. Tech. Res. 2018. Vol. 7. N 5. MS.ID.001567

[28] Микоян В.Д., Кубрина Л.Н., Ванин А.Ф. // Биофизика. 1994. T. 39. C. $915-918$.

[29] Van Faassen E.E., Koeners M.P., Joles J.A., Vanin A.F. // Nitric Oxide. 2008. Vol. 18. P. 279-286.

[30] Sato S., Tominaga T., Ohnishi T., Ohnishi S.T. // Brain Res. 1994. Vol. 647. P. 91-96.

[31] Tominaga T., Sato S., Ohnishi T., Ohnishi S.T. // J. Cerebral Blood Flow and Metaholism. 1994. Vol. 14. P. 715-722.

[32] Реутов В.П., Сорокина Е.Г., Швалев В.Н., Космачевская О.В., Крушинский А.Л., Кузенков В.С., Свиноа М.М., Косицын Н.С. // Успехи физиол. наук. 2012. Т. 43. № 4. C. 73-93.

[33] Ванин А.Ф. // Биофизика. 2017. Т. 62. Вып. 4. С. 629-656. [Vanin A.F. // Biophys. 2017. Vol. 62. N 4. P. 509-531.] 